\section{Desafios para a universalização dos serviços de água $e$ esgoto no Brasil}

\author{
Alceu Castro Galvão Junior ${ }^{1}$
}

Como citar: Galvão Junior AC. Desafios para a universalização dos serviços de água e esgoto no Brasil. Rev Panam Salud Publica. 2009;25(6):548-56.

Palavras-chave: saneamento básico/politicas, abastecimento de água, acesso universal a saneamento, Brasil.

\footnotetext{
1 Agência Reguladora do Ceará, Fortaleza (CE), Brasil. Correspondência: Rua Marcos Macedo 1350, apto. 702, CEP 60150-190, Fortaleza CE, Brasil. Fone: +55-85-3267.4853; e-mail: alceugalvao@uol.com.br, alceugalvao@arce.ce.gov.br
}

A universalização do acesso aos serviços de água e de esgoto é um objetivo legítimo das políticas públicas porque tem impactos importantes sobre a saúde, o ambiente e a cidadania. No Brasil, o déficit do setor de saneamento básico é elevado, sobretudo no que se refere ao esgotamento e tratamento de esgotos, com maior carência nas áreas periféricas dos centros urbanos e nas zonas rurais, onde está concentrada a população mais pobre. Conforme o censo de 2000 do Instituto Brasileiro de Geografia e Estatística (IBGE), dos 45 milhões de domicílios brasileiros, 35 milhões estavam conectados à rede de distribuição de água, 7 milhões possuíam poço ou nascente e 3 milhões possuíam outras fontes de abastecimento de água (1). Quanto ao esgotamento sanitário, dos quase 45 milhões de domicílios, 41,1 milhões tinham banheiro ou sanitário, enquanto 3,7 milhões eram desprovidos dessa infraestrutura (1).

Diversos são os fatores que explicam o déficit dos serviços de água e esgoto no país. Entre eles, destaca-se a fragmentação das políticas públicas e a carência de instrumentos de regulação (2). Com efeito, desde o final dos anos 1980, com a extinção do Plano Nacional de Saneamento, o Brasil não dispõe de uma política setorial consistente de água e esgoto (compreendida como um conjunto de leis, mecanismos de investimento e políticas regulatórias, entre outros). O principal impasse para o estabelecimento dessa política é a ausência de definição na constituição federal acerca da titularidade dos serviços nos sistemas integrados e nas regiões metropolitanas. Nesses casos, sistemas e infraestrutura são compartilhados por vários municípios, e a decisão sobre a titularidade se estadual ou municipal - encontra-se sob análise do Supremo Tribunal Federal.

Além disso, somente em 2007 foi promulgada a lei $\mathrm{n}^{\circ} 11445$, que estabelece as diretrizes nacionais para o saneamento básico. Entre os princípios dessa lei destaca-se a universalização, conceituada como a "ampliação progressiva do acesso de todos os domicílios ocupados ao saneamento básico" (3). Essa lei pretende ser o ponto de inflexão do setor, apontando mecanismos efetivos para a universalização dos serviços. A regulação, um dos principais instrumentos, deve ser realizada com independência e com autonomia administrativa, orçamentária e financeira da entidade reguladora, além de contemplar os aspectos de transparência, tecnicidade, celeridade e objetividade das decisões.

Dessa forma, o presente trabalho objetiva discutir os desafios postos para a universalização dos serviços de água e esgoto no Brasil, com ênfase nas questões institucionais do setor. 


\section{ASPECTOS LEGAIS E CONCEITUAIS DA UNIVERSALIZAÇÃO DOS SERVIÇOS}

O acesso aos serviços de saneamento básico é condição necessária à dignidade da pessoa humana e, particularmente, à sua sobrevivência. A participação do indivíduo na atividade econômica e social depende de uma vida saudável. Para tanto, é fundamental o acesso ao saneamento básico, assim como à moradia, à saúde e à educação.

No Brasil, o acesso universal aos serviços de água e esgoto está amparado de forma implícita e explícita em várias legislações, inclusive de áreas afins, como recursos hídricos, ambiente, saúde pública, defesa do consumidor e desenvolvimento urbano. Por exemplo, embora a constituição federal não reconheça de forma clara a universalidade do acesso aos serviços de água e esgoto como direito social, ao instituir como direitos a saúde e a moradia pode-se entender que contemple também o direito ao acesso aos serviços de saneamento. Isso porque, conforme ratificado amplamente na literatura (4-8), há correlação direta de causa e efeito entre saneamento e saúde. Essa interpretação está reforçada no artigo $1^{\circ}$ da constituição, que estabelece, entre os fundamentos da República Federativa, a cidadania e a dignidade da pessoa humana. Por outro lado, a lei n ${ }^{\circ} 11445 / 07$ é taxativa ao definir a universalização como princípio fundamental da prestação dos serviços públicos de saneamento básico. Apesar dos efeitos jurídicos que os princípios de uma lei acarretam, o seu caráter abrangente indica que suas consequências dependem das características de cada caso aplicado (9). Em outras palavras, a garantia legal para a universalização deverá estar assegurada nos marcos de cada concessão, mediante cláusulas e metas de expansão e de atendimento previstas nos contratos de concessão e de programa.

Quanto às legislações das áreas correlatas ao saneamento básico, é implícita a exigência ou recomendação de universalização dos serviços de água e esgoto. No que se refere à lei $n^{\circ} 8080 / 90$, do Sistema Único de Saúde (SUS), é obrigação desse sistema promover, proteger e recuperar a saúde, traduzida na promoção de ações de saneamento básico e de vigilância sanitária. Ademais, a lei $n^{\circ} 9433 / 97$, que estabelece a política nacional de recursos hídricos, define como objetivo a garantia da disponibilidade de água para gerações futuras. Tal fato decorre, principalmente, de ações de conservação de água e de tratamento de esgotos. Já o Código de Defesa do Consumidor, estabelecido na lei $n^{\circ} 8$ 078/ 90, determina que os serviços públicos devem ser prestados de forma adequada, entendida como aquela "que satisfaz as condições de regularidade, continuidade, eficiência, segurança, atualidade, generalidade, cortesia na sua prestação e modicidade das tarifas" (10). A política urbana é enfática em relação à garantia a cidades sustentáveis, que compreende, entre outros, o direito ao saneamento ambiental e à infraestrutura urbana. Por fim, a política nacional de meio ambiente (lei $n^{\circ} 6$ 938/81) objetiva a preservação, a melhoria e a recuperação da qualidade ambiental, o que também remete à necessidade de intervenções de saneamento básico.
A definição do conceito de universalização possui variáveis técnicas, sociais, políticas e econômicas, tendo sido usada e manipulada por diversos grupos para salvaguardar interesses específicos (11). Por exemplo, ao discutir o acesso universal aos serviços de telecomunicações, certos pesquisadores questionaram a centralização do debate sob a perspectiva e os anseios da oferta, especificamente os custos e as questões técnicas e regulatórias para se atingir a universalização (12). Por outro lado, pouca atenção tem sido dada para a demanda, usuários efetivos e potenciais, e para os impactos sociais e econômicos da universalização dos serviços (12).

Em relação ao saneamento básico, a perspectiva da demanda é importante, pois, com base nela, podem-se implantar tecnologias de fácil assimilação pela comunidade beneficiada, sob pena de ser a infraestrutura utilizada de forma inadequada ou tornar-se inoperante. Efetivamente, a falta de apropriação das intervenções técnicas de saneamento por parte da população dificulta a ampliação do acesso aos serviços de água e esgoto (13). No referente aos aspectos técnicos, a universalização não significa o uso exclusivo de tecnologias convencionais e pode, portanto, contemplar alternativas simplificadas e individuais.

Um estudo relata que as tecnologias simplificadas não podem ser analisadas de modo preconceituoso, ou como se fossem de segunda classe, para uso dos mais pobres (14). A título de exemplo, esses autores discorrem sobre o êxito da aplicação desse tipo de tecnologia em comunidades de renda elevada de vários países (14). Ainda conforme esse estudo, para os sistemas de esgotos, as soluções simplificadas geralmente são as mais viáveis técnica e economicamente para as populações de baixa renda e para áreas de alta densidade urbana. Assim, é necessário distinguir "tecnologias de baixo custo" de "atendimento de baixo padrão" (15), o que exigirá mudanças de comportamento de prestadores de serviço e usuários.

Da mesma forma, os padrões de qualidade devem ser adaptados às necessidades locais no sentido de se obter tarifas sustentáveis (16). No entanto, é preciso garantir requisitos mínimos de qualidade que não venham a prejudicar a saúde dos usuários, o ambiente e os recursos hídricos, bem como identificar os impactos causados pelas soluções simplificadas e alternativas, porquanto o mau uso dessas tecnologias pode agravar ainda mais as iniquidades causadas pela falta de acesso aos serviços.

Apesar das discussões, não há solução padrão de tecnologia para a universalização dos serviços. Essa decisão depende da análise de variáveis técnicas, sociais e econômicas envolvidas na implantação e na sustentabilidade dos serviços. A figura 1 apresenta considerações sobre as alternativas tecnológicas, simplificadas e convencionais possíveis para a universalização dos serviços de abastecimento de água e esgotamento sanitário.

Outro aspecto a ser considerado na definição dos critérios de universalização, especificamente em relação ao abastecimento de água, é a qualidade e a 
FIGURA 1. Tecnologias possíveis para a universalização dos serviços de água e de esgoto e etapas de implementação

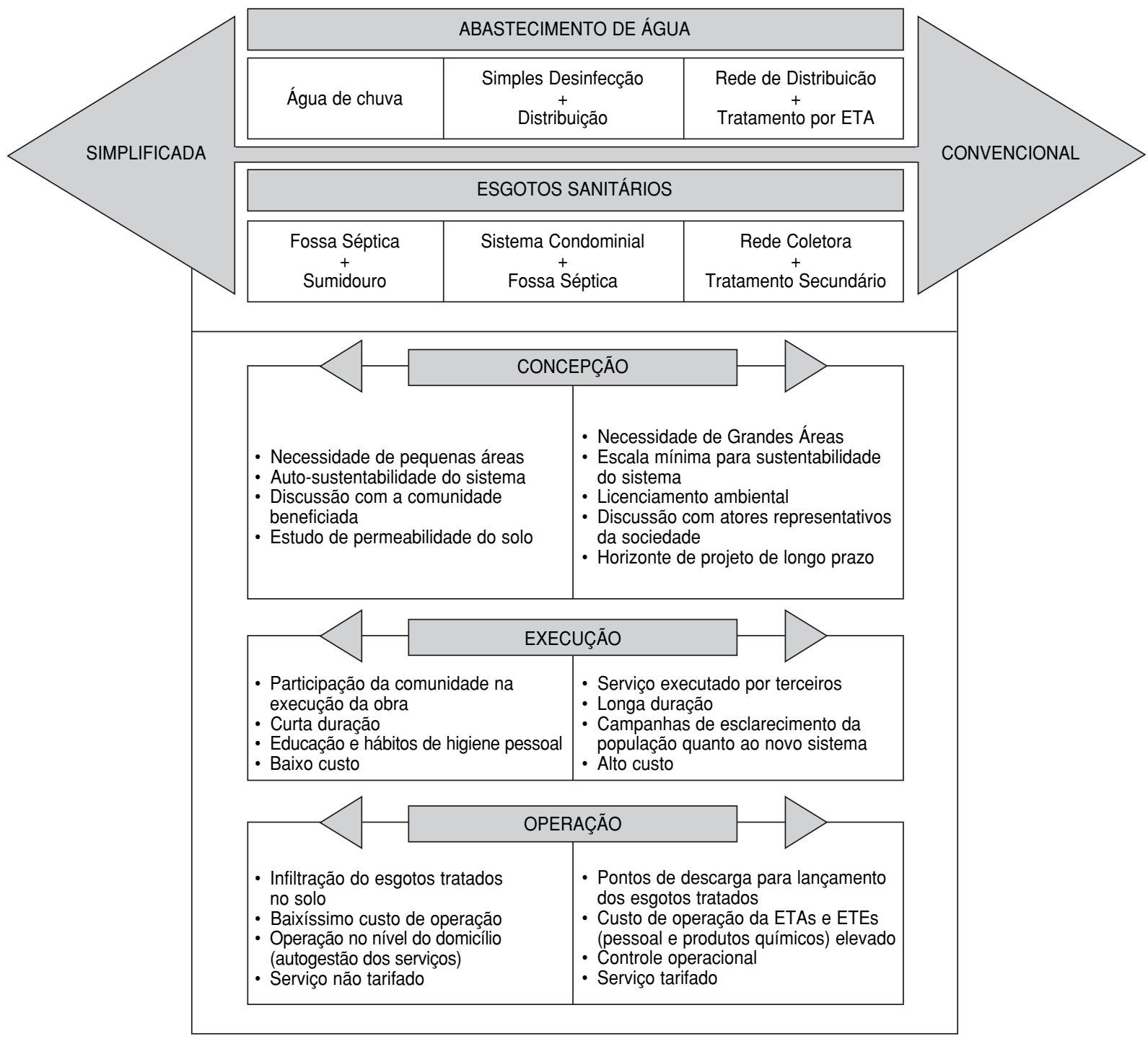

continuidade do fornecimento público. Tais condições, quando não satisfatórias, também propiciam riscos sanitários, por vezes até maiores quando os usuários são conectados a sistemas inadequados. Dessa forma, o espalhamento de redes pode permitir a conclusão errônea de que os serviços encontram-se universalizados, o que mascara as reais condições de qualidade e de quantidades de acesso a esses serviços (17). Os pesquisadores têm discutido a interpretação dos índices de cobertura por redes de distribuição de água, utilizados como indicador do acesso universal (18). Segundo esses pesquisadores, o indicador de cobertura não reflete as condições de continuidade e de qualidade do abastecimento de água, notadamente nas extremidades das redes, onde está localizada a população mais pobre. Isso mostra que a formulação das políticas públicas e o dimensionamento dos investimentos poderiam enfocar, por exemplo, a garantia da continuidade do fornecimento de água.

\section{PADRÕES DE ATENDIMENTO À UNIVERSALIZAÇÃO}

O principal estudo sobre critérios e custos de universalização no país foi conduzido pelo Ministério das Cidades (19), por meio do Programa de Modernização do Setor de Saneamento (PMSS). De acordo com esse estudo, o serviço é universalizado quando a oferta atende a $100 \%$ da demanda. O padrão de atendimento analisado nesse trabalho varia conforme o nível de agregação da população (urbano ou rural) e o tipo de sistema (abastecimento de água ou esgotos sanitários). No caso do abastecimento de água, a universalização se daria com ligações domiciliares e atendimento contínuo para as áreas urbanas, enquanto na área rural o padrão de atendimento dependeria de legislação específica (19). Em relação ao esgoto sanitário, a cobertura por rede varia conforme o tamanho da população a ser atendida, sendo admitidas soluções individuais (19). 
TABELA 1. Investimentos necessários para universalizar os serviços de água e esgoto no Brasil, 2010, 2015 e 2020

\begin{tabular}{lccr}
\hline \multirow{2}{*}{ Região } & \multicolumn{3}{c}{ Investimentos acumulados $(\mathrm{R} \$ \text { milhões })^{\mathrm{a}}$} \\
\cline { 2 - 4 } & 2010 & 2015 & 2020 \\
\hline Norte & 11275 & 13835 & 16307 \\
Nordeste & 27319 & 32267 & 37325 \\
Sudeste & 50349 & 62416 & 74404 \\
Sul & 23211 & 28098 & 33055 \\
Centro-Oeste & 11470 & 14507 & 17314 \\
Brasil & 123624 & 151124 & 178405 \\
\hline
\end{tabular}

Fonte: Ministério das Cidades, Secretaria Nacional de Saneamento Ambiental (19).

a US $\$ 1,00=R \$ 2,18$ (maio de 2009).

Ainda segundo esse estudo, serão necessários para universalizar até o ano de 2020 as cinco regiões geográficas do país cerca de 178 bilhões de reais em investimentos de expansão e reposição da infraestrutura (tabela 1).

Apesar da necessidade de aportes significativos para universalizar os serviços, segundo dados oficiais da Secretaria Nacional de Saneamento Ambiental, o governo federal desembolsou, mediante recursos onerosos e não onerosos, $\mathrm{R} \$$ 6,31 bilhões de 2003 a 2006 (20), isto é, uma média anual de R\$ 1,57 bilhão neste período. Caso se atenda a meta de universalização definida no estudo para o ano 2020, serão necessários R\$ 178,4 bilhões, ou seja, R \$ 8,9 bilhões ao ano. Entretanto, os recursos aportados no quadriênio representaram somente $17,6 \%$ do aporte anual necessário. Mesmo adicionando os investimentos oriundos de recursos próprios dos prestadores de serviço, o montante realizado ficou aquém do atendimento da meta de universalização para o ano de 2020.

Segundo a Associação das Empresas de Saneamento Básico Estaduais (AESBE), com esse nível de investimentos a universalização dos serviços de abastecimento de água só poderá ocorrer no ano de 2034, enquanto os esgotos sanitários seriam universalizados somente em 2054 (vale dizer que no referido estudo a universalização dos serviços de água e esgoto é apresentada de forma genérica, não sendo explicitados padrões de atendimento para o alcance desta meta) (21). Já o Instituto Trata Brasil apresenta um cenário mais pessimista quanto à universalização do acesso à rede geral de esgoto: de acordo com esse estudo, o acesso universal se dará apenas no ano de 2122 (22).

Para a Organização Mundial da Saúde (OMS) e o Fundo das Nações Unidas para a Infância (UNICEF), o padrão de atendimento é definido conforme a tecnologia utilizada (23). Na metodologia adotada por essas organizações, as tecnologias para abastecimento de água e de esgotos sanitários são classificadas em melhoradas ${ }^{2}$

\footnotetext{
2 O termo "melhorado" (improved, em inglês) substituiu os termos "segura" (safe, em inglês) e "adequado" (adequate, em inglês), antes utilizados pela ONU como padrões, visto que as pesquisas realizadas no âmbito dos domicílios não conseguiam comprovar se as tecnologias eram seguras ou adequadas.
}

e não melhoradas. As populações atendidas por tecnologias melhoradas são consideradas universalizadas pelos serviços. Entre as tecnologias melhoradas para os serviços de água estão conexão doméstica, fonte pública e poço escavado (23). Já para os esgotos sanitários, estão incluídos a conexão à rede pública e ao sistema séptico, além do vaso sanitário com descarga (23).

Caso essas tecnologias não sejam acompanhadas de padrões de qualidade e de continuidade, o conceito de "melhorado" definido pela OMS e pelo UNICEF pode resultar em avaliações irreais quanto ao atendimento dos serviços. Desse modo, os critérios definidos pelo estudo do Ministério das Cidades, associados a padrões de qualidade, estão mais focados na realidade nacional.

\section{PANORAMA DOS SERVIÇOS NO BRASIL}

No Brasil, o déficit dos serviços de água e esgoto é mais acentuado nas populações de baixa renda, as quais apresentam maiores problemas de saúde pública $(13,18,24,25)$. Este déficit evidencia características de desigualdades sob os aspectos inter-regional, renda familiar e localização do domicílio. Conforme dados da Pesquisa Nacional por Amostragem de Domicílios (PNAD) 2005 (26), o abastecimento por redes, mais adequado do ponto de vista sanitário, é maior nas regiões Sul e Sudeste, nos extratos de renda elevados e nas áreas urbanas. Por outro lado, a avaliação da população coberta apenas identifica se o domicílio estava ligado à rede de distribuição de água, não fornecendo informações acerca da qualidade e da continuidade do abastecimento. Portanto, os percentuais apresentados pela PNAD (26) podem estar sobrevalorizados quanto às reais condições de universalização.

Já a distribuição do acesso aos serviços de esgoto por rede coletora de acordo com região, renda e área urbana ou rural do domicílio acompanha o mesmo perfil apresentado quanto ao abastecimento de água por rede, com o agravante de a rede coletora ter menor cobertura. No entanto, as desigualdades de cobertura por redes de esgoto são maiores do que as de redes de água. Por exemplo, quanto à distribuição regional, o Sudeste possui $77,4 \%$ de cobertura por redes de esgoto, enquanto as regiões Nordeste, Sul e Norte têm, respectivamente, $27 \%$, 25,9\% e $4 \%$ de cobertura. Da mesma forma, em relação à renda, a população com renda superior a 20 salários mínimos tem 76,6\% de acesso às redes de esgoto, mais do que o dobro das famílias com menos de 2 salários mínimos.

A definição de rede coletora abrange ainda o esgotamento por galerias de águas pluviais, assim como o lançamento desses esgotos in natura nos corpos d'água. Ao considerar esse conceito, entende-se que os índices apresentados para o esgotamento sanitário por redes estão acima dos valores reais do que seria a condição adequada, ou seja, esgotamento por redes coletoras e tratamento e disposição final dos esgotos. Não obstante, ressalta-se, quando viável técnica e economicamente, tanto para os serviços de água como para os 
de esgoto, que as soluções simplificadas também são consideradas adequadas.

Ao se comparar o saneamento básico com os demais setores da infraestrutura do país (26-28), tem-se que a distribuição de energia elétrica está próxima de atingir a universalização e que a telefonia apresenta ritmo de expansão bastante elevado, em virtude do incremento na quantidade de telefones móveis a partir do ano 2000. No período de 1991 a 2005, a quantidade de telefones nos domicílios brasileiros aumentou cerca de $500 \%$, enquanto a cobertura de água por rede geral foi ampliada em 77\%. Já para os domicílios atendidos por rede geral para esgotamento sanitário, o aumento foi próximo a $100 \%$.

Entre as causas que justificam o menor avanço da infraestrutura de saneamento básico em relação aos setores de energia e telecomunicações estão a dispersão na aplicação das políticas setoriais por diversos órgãos do governo federal, indefinição da titularidade, dependência de elevados investimentos e falta de articulação intergovernamental para execução de reformas setoriais (29). Há também a fragmentação de políticas públicas e problemas com a concessão e a regulação dos serviços $(2,30)$. Além disso, os recursos necessários para a expansão dos serviços de saneamento são superiores aos dos demais setores (25). Conforme Jordan (31), os investimentos em saneamento básico são em média três a quatro vezes maiores do que os investimento em energia, embora o autor não explicite os critérios de cálculo utilizados para dimensionar os investimentos.

\section{DESAFIOS PARA A UNIVERSALIZAÇÃO DOS SERVIÇOS DE ÁGUA E ESGOTO}

\section{Mecanismos das políticas públicas de universalização}

Dispor de serviços de água e esgoto, com áreas totalmente cobertas por redes, não necessariamente significa tê-los universalizados. Além das questões relativas à qualidade e à continuidade dos serviços, o acesso à infraestrutura é muitas vezes limitado pela falta de capacidade de pagamento das tarifas pela população. Diante disso, há a necessidade de políticas públicas redistributivas, que desloquem de forma consciente os recursos financeiros e os de outras naturezas entre camadas sociais e grupos da sociedade (32).

Os mecanismos de implantação de políticas públicas redistributivas, tais como fundos, subsídios e recursos a fundo perdido, são essenciais para a universalização na maioria dos municípios brasileiros e, ao longo das últimas décadas, foram responsáveis pelo incremento da cobertura da infraestrutura. A par disso, vários autores apontam caminhos para a universalização dos serviços de água e esgoto.

Motta e Moreira, por exemplo, defendem a utilização de subsídios diretos mediante programas sociais (33). De acordo com esses autores, a tarifa dos serviços seria composta de duas partes: a primeira, fixa, em função de consumo mínimo e paga diretamente à concessionária pelo gestor do programa social; a segunda, variável, em função da diferença efetivamente consumida em relação ao consumo mínimo e com pagamento feito pelo usuário. De outra forma, os investimentos a fundo perdido, combinados ou não com mecanismos tarifários ou tributários compensatórios, podem viabilizar a universalização (34).

Os recursos não onerosos, oriundos do orçamento geral da União, são os mais representativos dos investimentos públicos no setor. Para o período 2003 a 2006, esses desembolsos representaram $49 \%$ do total de recursos comprometidos, com a maior parcela destinada para as regiões mais carentes e para os municípios pequenos, áreas rurais e minorias étnico-sociais (20). Apesar de a destinação de verbas estar focada nas áreas mais deficitárias de infraestrutura sanitária, a qualidade do gasto público é reconhecida pelo próprio governo como um dos entraves para se atingir a eficiência e a eficácia na alocação dos recursos (20). A qualidade do gasto está relacionada ao uso indevido dos recursos públicos, à utilização de critérios políticos na definição da prioridade dos investimentos e à ausência de eficácia da infraestrutura instalada, o que é mais uma consequência da fragilidade institucional do setor.

Já outro pesquisador advoga que a política adequada seria a implantação de fundos de universalização por área de concessão a partir de um percentual arrecadado da receita bruta operacional do prestador de serviços da área, cuja gestão caberia ao regulador local (35). Ainda, para as localidades onde não fosse possível levantar recursos para a formação do fundo, os investimentos seriam custeados com recursos do governo federal.

No Brasil, o subsídio cruzado é amplamente praticado mediante a agregação em escala estadual da prestação dos serviços em uma única empresa, que distribui subsídios dos municípios mais ricos para os mais pobres e das categorias de usuários de maior poder aquisitivo (indústrias e comércio) para os de menor poder (residenciais). A aplicação desse mecanismo é alvo de críticas, sobretudo diante da possibilidade de inversão de prioridades dos investimentos com os subsídios alocados. Como resultado, as famílias com rendas superiores a 10 salários mínimos têm $50 \%$ mais cobertura de abastecimento de água e $100 \%$ mais de rede de esgoto do que as famílias com menos de 2 salários mínimos (33). Isso, segundo os autores (33), comprova a desfocalização do mecanismo de subsídios cruzados. Tal mecanismo também tem gerado disputas entre estados e municípios, pois os recursos arrecadados com a cobrança em municípios superavitários destinam-se à manutenção dos serviços e ao atendimento do crescimento vegetativo, com o excedente transferido para outros municípios (36).

Contudo, o desvirtuamento na aplicação dos subsídios cruzados pode estar associado a diversos fatores, como falta de controle social e ausência de transparência na distribuição dos subsídios e no poder decisório do prestador de serviços quanto à definição dos 
critérios de repartição desses recursos. Legalmente, as políticas redistributivas devem ser definidas pelo titular dos serviços, que possui legitimidade para estabelecimento dessas políticas.

Efetivamente, a tarifa deveria ser o principal mecanismo de custeio dos serviços e de alavancagem de recursos para investimento (24). Entretanto, ela é insuficiente para atender às demandas de universalização, que exigem recursos fiscais para provisão de infraestrutura.

De modo geral, as discussões acerca dos mecanismos redistributivos abrangem os subsídios relativos às tarifas ou à expansão das redes. Contudo, não se pode desconsiderar a importância do subsídio na interligação da rede de água, cujo serviço é comumente tarifado pelas concessionárias e, portanto, se constitui num obstáculo ao acesso dos mais pobres (37). Dessa forma, o impacto causado pelo subsídio à conexão é maior que aquele relacionado ao consumo (16). Assim, diante da atual capacidade instalada, há margem de ampliação da infraestrutura, sobretudo nas zonas urbanas, cobertas integralmente por redes, mas com vazios de atendimento localizados nos bolsões de pobreza. Este é mais um desafio para o setor.

Independentemente dos mecanismos adotados, alguns requisitos são essenciais para o êxito das políticas redistributivas. A princípio, é preciso definir o foco da política que, indubitavelmente, deve ser o atendimento aos mais pobres. A transparência é outro requisito fundamental, e tornaria possível o monitoramento da eficácia desse mecanismo (38). Quem subsidia, quais os beneficiados, qual o volume de recursos envolvidos e quais os custos de transação na alocação dos recursos são questões a serem respondidas. Ademais, a realização de investimentos sem a definição de mecanismos claros pode levar ao desperdício de recursos públicos, além da implantação de sistemas ineficazes tanto do ponto de vista técnico como dos resultados relacionados à saúde pública.

Deve-se ainda considerar as bases federativas do Estado brasileiro e a crise fiscal que há tempos assola estados e municípios. Dessa forma, a efetividade de qualquer mecanismo redistribuitivo depende da participação direta da União no financiamento das políticas. A promoção da melhoria do saneamento básico é competência comum da União, estados e municípios. Desses entes federados, os maiores aportes de recursos provêm da União; porém, esses investimentos são marcados pela instabilidade. A própria falta de marco setorial e a localização das políticas públicas do setor em diversos órgãos e ministérios ao longo das últimas décadas contribuíram para a redução da eficácia dos mecanismos redistributivos.

As opções dos mecanismos apresentados mostram vantagens e desvantagens para cada alternativa. Mostram ainda que não existe apenas uma opção para aplicação nas diferentes realidades brasileiras. $\mathrm{O}$ importante é que, seja qual for o mecanismo utilizado, devem-se resguardar as premissas fundamentais para o êxito das políticas de universalização, tais como a transparência e o controle social.

\section{Titularidade dos serviços}

Vários autores apontam que a ausência de definição explícita na constituição acerca da titularidade dificulta o avanço da expansão e da melhoria da prestação dos serviços $(25,39)$. Ao longo das três últimas décadas, a questão da titularidade não fez parte da agenda institucional do setor, mesmo após a constituição de 1988. Isso ocorreu, em primeiro lugar, porque os progressos na cobertura dos serviços, sobretudo no abastecimento de água, contemplaram os interesses dos grandes municípios pertencentes aos sistemas integrados e metropolitanos. Ademais, diante da fragilidade dos instrumentos contratuais, os prestadores de serviço assumiram as funções de regulação e de elaboração de políticas, conquistando autonomia para definir os rumos das concessões que, apesar de nem sempre estarem em sintonia com os objetivos da sociedade, evitavam conflitos com os municípios. Efetivamente, a ausência de participação dos municípios repercutiu de forma negativa nos resultados alcançados, mas, ao mesmo tempo, esses entes federados não detinham $e x$ pertise para o exercício da titularidade, gerando um círculo vicioso na definição dos papéis institucionais.

Porém, com a escassez de recursos para investimentos, principalmente no tratamento de esgotos, e com o término dos contratos de concessão, situação ocorrida desde o final dos anos 1990, os municípios passaram a exigir seus direitos e assumir as prerrogativas de titular dos serviços. As disputas em torno da titularidade estão focadas nos sistemas integrados e nas regiões metropolitanas, consideradas pelos Estados como sistemas de interesse comum.

Deve-se ressaltar que o debate sobre titularidade não se configura objeto desta discussão. ${ }^{3}$ Mas, como a questão se constitui em um dos grandes desafios do setor, é preciso avançar rumo à universalização, independentemente dessa definição. Ademais, essa discussão relegou a segundo plano outros temas fundamentais para o desenvolvimento do saneamento, como planejamento, regulação, operação e financiamento (40).

A indefinição acerca da titularidade também contribui para o atraso no estabelecimento de políticas públicas para o setor (41). No Brasil, a falta de política setorial consistente para o saneamento se verifica desde o final dos anos 1980, quando do término do Plano Nacional de Saneamento (PLANASA). Dos setores da infraestrutura, o saneamento foi o último a dispor de política nacional, mediante a lei $n^{\circ} 11445$. Efetivamente, a desarticulação das políticas setoriais de estados e municípios colabora para agravar ainda mais o quadro institucional do setor (36). No saneamento

\footnotetext{
A titularidade vem sendo debatida pelo Supremo Tribunal Federal, em duas ações diretas de inconstitucionalidade (ADIN) que tramitam em processo de julgamento: $\mathrm{ADIN} \mathrm{n}^{\circ} 1$ 842, referente à ação impetrada pelo Partido Democrático Trabalhista contra o Governo e a Assembleia Legislativa do Estado do Rio de Janeiro; e ADIN $n^{\circ}$ 2 077, arguida pelo Partido dos Trabalhadores contra a Assembleia Legislativa do Estado da Bahia.
} 
TABELA 2. Funções do titular e do regulador de serviços de saneamento conforme a lei ${ }^{\circ} 11445 / 2007$, Brasil

\begin{tabular}{ll}
\hline \multicolumn{1}{c}{ Titular } & \multicolumn{1}{c}{ Regulador } \\
\hline Elaborar planos de saneamento básico & Verificar o cumprimento dos planos de saneamento básico \\
Delegar a prestação dos serviços & $\begin{array}{l}\text { Garantir o cumprimento das condições e metas estabelecidas; garantir a fiel interpretação } \\
\text { dos contratos }\end{array}$ \\
Fixar direitos e deveres dos usuários & $\begin{array}{l}\text { Normatizar aspectos técnicos, econômicos e sociais da prestação dos serviços; receber e } \\
\text { se manifestar sobre as reclamações dos usuários; dar publicidade aos direitos e deveres } \\
\text { dos usuários; permitir acesso às informações sobre os serviços prestados }\end{array}$ \\
Estabelecer mecanismos de controle social & $\begin{array}{l}\text { Dar transparência às ações, baseada em sistemas de informações e processos decisórios } \\
\text { institucionalizados; dar publicidade a relatórios, estudos e decisões }\end{array}$ \\
Definir nos contratos regras para fixação, & $\begin{array}{l}\text { Definir as pautas das revisões tarifárias; estabelecer regras e critérios de estruturação do } \\
\text { sistema contábil e plano de contas; definir e fixar tarifas; auditar e certificar anualmente os } \\
\text { reajuste e revisão de tarifas }\end{array}$ \\
investimentos realizados, os valores amortizados, a depreciação e os respectivos saldos; \\
estabelecer normas e mecanismos sobre tarifas, pagamentos e subsídios para prestadores \\
que realizem atividades interdependentes \\
Intervir e retomar a operação dos serviços
\end{tabular}

Fonte: Brasil, lei $\mathrm{n}^{\circ} 11$ 445, de 5 de janeiro de 2007 (3).

básico houve retardo de cerca de uma década em relação aos demais serviços de infraestrutura para dispor do seu próprio marco legal, o que demonstra a falta de prioridade política com o setor. Como consequência, no âmbito estadual são reportadas somente sete políticas públicas entre os 26 estados e o Distrito Federal. Ademais, nem todas essas políticas estão regulamentadas ou implementadas.

\section{Regulação da prestação dos serviços}

Na busca da universalização, a regulação pode exercer vários papéis. Um deles é fazer cumprir, por meio das políticas regulatórias, as macrodefinições estabelecidas nas políticas públicas setoriais decididas no âmbito dos poderes executivo e legislativo. Outro papel seria desenvolver mecanismos que incentivem a eficiência das empresas prestadoras de serviço, pois, desse modo, mais recursos poderão ser canalizados para a expansão da infraestrutura. Além disso, a regulação proporciona um ambiente mais estável para a realização de investimentos públicos e privados no setor. Assim, não se espera que a regulação venha remover todos os obstáculos à universalização, mas é preciso considerá-la no conjunto de soluções como parcela significativa para a consecução deste objetivo.

No Brasil, a lei $\mathrm{n}^{\circ} 11445 / 2007$, que tem como objeto estabelecer diretrizes nacionais para o saneamento básico e a política federal do setor, definiu a regulação como condição para a validade dos contratos. Esse objeto traz ainda significativas repercussões sobre a legislação subnacional, sobretudo relacionada à regulação da prestação dos serviços. A tabela 2 resume algumas das funções definidas para o titular dos serviços e para o ente regulador na lei.

$\mathrm{O}$ atendimento às funções regulatórias (tabela 2) exigirá do ente regulador uma elevada capacidade técnica e operacional, além de recursos financeiros.
Porém, a não definição, na lei, de instrumentos que assegurem a autonomia orçamentária e financeira põe em risco a viabilidade do cumprimento desse princípio (42), fundamental para a efetividade da regulação.

Efetivamente, o financiamento da regulação nas agências com competência para atuar no saneamento é realizado por taxas previstas nos marcos setoriais subnacionais. As taxas de regulação determinadas em alguns marcos legais para o setor variam de 1 a $3 \%$ para agências municipais, enquanto que, nas estaduais, as taxas estão em torno de $0,5 \%$ do faturamento das concessionárias.

Apesar de se considerar que a viabilidade da regulação não se limita somente ao custeio da atividade, este é um dos pontos fundamentais para garantir sua implementação nos moldes da lei $\mathrm{n}^{\circ} 11445 / 2007$. Assim, ao analisar 2523 municípios brasileiros com até 200000 economias ativas de água e esgoto cujos serviços são operados por concessionárias estaduais, pesquisadores concluíram que a regulação, conforme estabelecido nessa lei, custeada por uma taxa de 3\% do faturamento das concessionárias, é viável somente em 65 municípios (43).

Além dos aspectos financeiros, diversos autores relatam outras razões que dificultam a regulação setorial por parte dos municípios. A principal delas é a falta capacidade técnica $(35,38,39)$. Como alternativa, a lei $n^{\circ} 11445 / 2007$ permite a delegação da regulação a qualquer ente constituído dentro dos limites do respectivo Estado. Desse modo, fica facultado aos titulares não capacitados para o exercício dessa atividade ou não interessados em exercê-la por ente regulador próprio delegar a agência estadual ou a consórcio criado para este fim. Deve-se ainda ressaltar que a participação dos municípios na gestão dos serviços abrange também a definição da política setorial configurada, sobretudo por meio dos planos de saneamento básico, conforme descrito no artigo $9^{\circ}$ da lei $\mathrm{n}^{\circ}$ $11445 / 2007$. 


\section{CONCLUSÃO}

Os desafios postos à universalização dos serviços de água e esgoto no Brasil são enormes, com necessidade de investimentos em torno de $\mathrm{R} \$ 178$ bilhões até o ano 2020. Apesar do significativo montante de recursos, são as questões institucionais do setor, notadamente os mecanismos de políticas públicas, a titularidade e a regulação dos serviços, as que mais dificultam a ampliação dos índices de cobertura, inibindo investimentos em expansão e reposição da infraestrutura sanitária.

Nos setores onde os problemas institucionais foram solucionados, como energia e telefonia, já são reportados índices próximos à universalização, como no caso da energia, além do avanço acelerado na expansão dos serviços de telecomunicações.

Assim, mesmo não definidas todas as lacunas institucionais com a edição da lei 11 445/2007, esperase que a regulação, obrigatória para a validade dos contratos, incentive a melhoria de eficiência dos prestadores de serviço, a transparência dos mecanismos de políticas públicas e o atendimento de metas de universalização, que deverão ser previstas nos marcos regulatórios subnacionais.

\section{SYNOPSIS}

\section{Challenges for providing universal access to water and sewer services in Brazil}

The present article discusses the challenges that must be met to achieve universal access to water and sewer services in Brazil. First, the principles concerning the topic in Brazilian law are presented, as well as theoretical aspects including concepts relating to universalization and the standards of service employed. The main challenges for the universalization of water and sewer services in Brazil include the definition and establishment of public policies and designation of responsibility for the provision and regulation of these services. Despite the significant amount of resources available for universalization in Brazil, institutional issues in this sector hinder the broadening of the coverage, inhibiting the investments in sanitation infrastructure.

Key words: basic sanitation/policies, water supply, universal access to sanitation, Brazil.

\section{REFERÊNCIAS}

1. Instituto Brasileiro de Geografia e Estatística. Censo demográfico 2000. Rio de Janeiro: IBGE; 2001. Disponível em: http:// www.ibge.gov.br/home/estatistica/ populacao/censo2000/defauld.shtm. Acessado em maio de 2009.

2. Nascimento NO, Heller L. Ciência, tecnologia e inovação na interface entre as áreas de recursos hídricos e saneamento. Eng San Ambient. 2005;10(1):36-48.

3. Brasil. Lei $n^{\circ} 11.445$, de 5 de janeiro de 2007. Diário Oficial da União 2007. 8 de janeiro:3. Disponível em: http://www. planalto.gov.br/ccivil_03/_ato20072010/2007/lei/111445.htm. Acessado em maio de 2009 .

4. Gleick PH. The human right to water. Water Policy. 1999;1(5):487-503.

5. Heller L, Colosimo EA, Antunes CMF. Condições de saneamento ambiental e impacto na saúde: um estudo casocontrole. Rev Soc Bras Med Trop. 2003; 36(1):41-50.

6. Hutton G, Haller L. Evaluation of the costs and benefits of water and sanitation improvements at the global level. Genebra: WHO; 2004. Disponível em: http://smap.ew.eea.europa.eu/media server/files/6/A/sanitation_WHO.pdf. Acessado em maio de 2009.

7. Soares SRA, Bernardes RS, Cordeiro Netto OM. Relações entre saneamento, saúde pública e meio ambiente: elementos para formulação de um modelo de planejamento em saneamento. Cad Saude Publica. 2002;18(6):1713-24.

8. Teixeira JC, Pungirum MEMC. Análise da associação entre saneamento e saúde nos países da América Latina e do Ca- ribe, empregando dados secundários do banco de dados da Organização PanAmericana de Saúde - OPAS. Rev Bras Epidemiol. 2005;8(4):365-76.

9. Aragão AS. Regulação da economia: conceito e características contemporâneas. Em: Peci A, ed. Regulação no Brasil: desenho, governança e avaliação. São Paulo: Atlas; 2007. Pp. 31-71.

10. Brasil. Lei $\mathrm{n}^{\circ} 8.987$, de 13 de fevereiro de 1995. Diário Oficial da União 1995. 14 de fevereiro: 3-6. Disponível em: www. aneel.gov.br/cedoc/lei19958987.pdf. Acessado em maio de 2009.

11. Blackman CR. Universal service: obligation or opportunity? Telecommunications Policy. 1995;19(3):171-6.

12. Gharam S, Cornford J, Marvin S. The socio-economic benefits of a universal telephone network: A demand-side view of universal service. Telecommunications Policy. 1996;20(1):3-10.

13. Heller L, Nascimento NO. Pesquisa e desenvolvimento na área de saneamento no Brasil: necessidades e tendências. Eng Sanit Ambient. 2005;10(1): 24-35.

14. Paterson C, Mara D, Curtis T. Pro-poor sanitation technologies. Geoforum. 2007; 38(5):901-7.

15. Brasil, Secretaria de Política Urbana, Instituto de Pesquisa Econômica Aplicada (IPEA), Núcleo de Pesquisas em Informações Urbanas da Universidade de São Paulo. Fundamentos e proposta de ordenamento institucional. Brasília: Ministério do Planejamento e Orçamento; 1995. (Série Modernização do Setor Saneamento, vol. 1).
16. Trémolet $S$, Hunt $C$. Taking account of the poor in water sector regulation. Washington: World Bank; 2006. Disponível em: http://siteresources.world bank.org/INTWSS/Resources/WN11. pdf. Acessado em maio de 2009.

17. Silva RT. Público e privado na oferta de infra-estrutura urbana no Brasil. Em: Anuário Gedim 2002 (Cidades, serviços e cidadania). Programa Interdisciplinar Globalização Econômica e Direitos no Mercosul (Gedim), Unesco/MOST. Rio de Janeiro: Lúmen Júris; 2002. Pp. 53-112.

18. Silva RT, Machado L. Serviços urbanos em rede e controle público do subsolo novos desafios à gestão urbana. Sao Paulo Perspec. 2001;15(1):102-11.

19. Brasil, Ministério das Cidades, Secretaria Nacional de Saneamento Ambiental. Dimensionamento das necessidades de investimento para a universalização dos serviços de abastecimento de água e de coleta e tratamento de esgotos sanitários no Brasil. Brasília: Ministério das Cidades; 2003.

20. Brasil, Ministério das Cidades, Secretaria Nacional de Saneamento Ambiental. Investimentos federais em saneamento. Brasília: Ministério das Cidades; 2007.

21. Associação das Empresas de Saneamento Básico Estaduais. Financiamento de investimentos em saneamento básico. Brasília: AESBE; 2006. Disponível em: www. sep.org.br/artigo/1257_41690dea7b536 e54cd8cd81000945f6f.pdf?PHPSESSID= fe7da83c472bf5dff0d4fe1e116ed324. Acessado em maio de 2009.

22. Instituto Trata Brasil. Trata Brasil: saneamento e saúde. Rio de Janeiro: FGV/ 
IBRE; 2007. Disponível em: www3.fgv. br/ibrecps/CPS_infra/texto.pdf. Acessado em maio de 2009.

23. World Health Organization. United Nations Children's Fund. Global water supply and sanitation assessment 2000 report. Nova Iorque: WHO; 2000.

24. Pena DS, Abicalil MT. Saneamento: os desafios do setor e a política de saneamento. Em: IPEA. Infra-estrutura: perspectivas de reorganização, saneamento. Brasília: IPEA; 1999. Disponível em: http://www.ipea.gov.br/pub/infra estrutura/saneamento/san_parte4.pdf. Acessado em 6 de maio de 2006.

25. Turolla FA, Ohira TH. Saneamento básico: experiência internacional e avaliação de propostas para o Brasil. São Paulo: CNI; 2006.

26. Instituto Brasileiro de Geografia e Estatística. Pesquisa nacional por amostra de domicílios: 2005. Rio de Janeiro: IBGE; 2006. Disponível em: http://www.ibge. gov.br/home/estatistica/populacao/ trabalhoerendimento/pnad2005/default. shtm. Acessado em maio de 2009.

27. Instituto Brasileiro de Geografia e Estatística. Pesquisa nacional por amostra de domicílios: 2001. Rio de Janeiro: IBGE; 2002.

28. Instituto Brasileiro de Geografia e Estatística. Estatísticas do século XX. Rio de Janeiro: IBGE; 2003. Disponível em: http:// www.ibge.gov.br/home/presidencia/ noticias/29092003estatisticasecxx.shtm. Acessado em maio de 2009.

29. Zveibil VZ. Reforma do estado e a gestão do saneamento: uma trajetória incompleta [tese]. Rio de Janeiro: Escola
Nacional de Saúde Pública, FIOCRUZ; 2003.

30. Toneto Jr. R, Saiani CCS. Restrições à expansão dos investimentos no saneamento básico brasileiro. REN. 2006; 37(4):572-91.

31. Jordan JL. Introduction to water: economic concepts, water supply and water use. Georgia: Department of Agricultural \& Applied Economics; 1998. (Georgia Water Series, Issue $1, n^{\circ} 98-13$ ).

32. Frey K. Políticas públicas: um debate conceitual e reflexões referentes à prática da análise de políticas públicas no Brasil. Brasília: IPEA; 2000. Disponível em: http://www.ipea.gov.br/pub/ppp/ ppp21/Parte5.pdf. Acessado em 6 de maio de 2006

33. Seroa da Motta R, Moreira A. Efficiency and regulation in the sanitation sector in Brazil. Utilities Policy. 2006;14(3):185-95.

34. Parlatore AC. Privatização do setor de saneamento no Brasil. Disponível em http://www.bndes.gov.br/conheci mento/ocde/ocde08.pdf. Acessado em 29 de junho de 2006.

35. Turolla FA. Política de saneamento: avanços recentes e opções futuras de políticas públicas. Brasília: IPEA; 2002. Disponível em http://www.ipea.gov.br/ $\mathrm{pub} / \mathrm{td} / 2002 / \mathrm{td}$ 0922.pdf. Acessado em 6 de maio de 2006.

36. Ogera RC, Philippi Jr A. Gestão dos serviços de água e esgoto nos municípios de Campinas, Santo André, São José dos Campos e Santos, no período de 1996 a 2000. Eng Sanit Ambient 2005;10(1): 72-81.
37. Vargas MC. O negócio da água. São Paulo: Annablume; 2005.

38. Seroa da Motta R. Questões regulatórias do setor de saneamento no Brasil. Rio de Janeiro: IPEA; 2004. Disponível em http://www.ipea.gov.br/sites/000/ 2 /publicacoes/notastecnicas/notas tecnicas5.pdf. Acessado em 19 de maio de 2007.

39. Conforto G. A regulação e a titularidade dos serviços de abastecimento de água e esgotamento sanitário no Brasil. Rev Adm Publica. 2000;34(5):165-80.

40. Cunha AS, Nahoum AV, Mendes $\mathrm{CH}$, Coutinho DR, Ferreira FM, Turolla FA. Poder concedente e marco regulatório no saneamento básico. São Paulo: FGV. 2006. Disponível em: http:/ /www. direitogv.com.br/AppData/Publication/ direito\%2010.pdf. Acessado em maio de 2009. Cadernos Direito GV. Vol 2, n 2.

41. Pires JCL, Piccinini MS. A regulação dos setores de infra-estrutura no Brasil. Rio de Janeiro: BNDES; 1999. Disponível em http://www.bndes.gov.br/conheci mento/livro/eco90_07.pdf. Acessado em 18 de agosto de 2006.

42. Mukai ST. Da regulação. Em: Mukai T, ed. Saneamento básico: diretrizes gerais-comentários gerais à Lei 11.445 de 2007. Rio de Janeiro: Lumen Júris; 2007. Pp. 59-71.

43. Galvão Junior AC, Turolla FA, Paganini WS. Viabilidade da regulação subnacional dos serviços de abastecimento de água e esgotamento sanitário sob a Lei 11.445/2007. Eng Sanit Ambient. 2008; 13(2):134-43.

\section{Manual de esterilización para centros de salud}

Este manual ha sido elaborado con el propósito de informar al personal de salud acerca de los protocolos y procedimientos simples desarrollados para prevenir las infecciones nosocomiales dentro y desde la central de esterilización.

La central de esterilización juega un papel muy importante en la prevención de las infecciones adquiridas en el hospital, porque tales infecciones han sido asociadas con una desinfección inapropiada de objetos reusables incluyendo el equipo endoscópico, el equipo de cuidado respiratorio, los transductores y los equipos de hemodiálisis reusables.

Esta publicación está dirigida al personal técnico responsable de estos procesos y así garantizar la prevención de las infecciones nosocomiales.

\section{Adquiera esta publicación por medio de la librería en línea de la OPS:} http://publications.paho.org; correo electrónico: paho@brightkey.net;

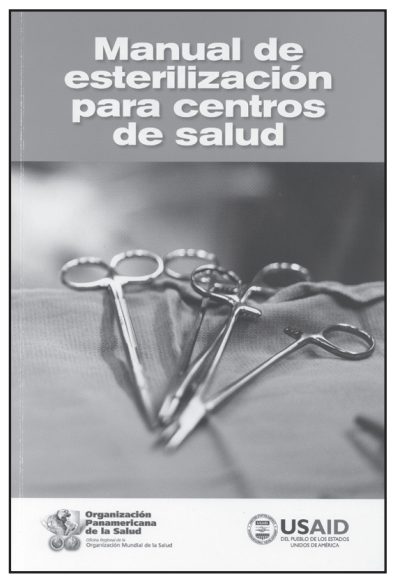

Fax: (301) 209-9789; Oficina de país de la OPS/OMS

2008, $184 \mathrm{pp}$

ISBN: 9789275329269

US\$ 10.00 en América

Latina y el Caribe/

US\$ 18.00 en el resto del

mundo

Código: OT 212 